\title{
Visualization and pressure distribution of gas-liquid flow in $3 / 4$ inch plexyglass pipe diameter with the slope orientation upward, horizontal and downward
}

\author{
Dewi Puspitasari ${ }^{*}$, Marwan Marwani ${ }^{1}$, Ichsan Ramdani ${ }^{1}$, Ridho Mardhan Hadi ${ }^{1}$ \\ ${ }^{1}$ Mechanical Engineering Department, Faculty of Engineering, Universitas Sriwijaya, Inderalaya Ogan Ilir, Indonesia
}

\begin{abstract}
The flowing phase in the pipe is affecting on the continuity of fluid transport process, this is due to the interaction when the fluid mixture flowing at a certain superficial velocity. Therefore it will be studied the distribution of pressure and flow pattern of a transparent pipe (plexiglass) $3 / 4$ inches, and its influence on the orientation of the pipe $10^{\circ}, 5^{\circ}, 0^{\circ},-5^{\circ}$ and $-10^{\circ}$ by the experimental equipment. The research was carried out experimentally with the water flow $10-20 \mathrm{lpm}$ and air flow $5-15 \mathrm{lpm}$. Results showed the flow pattern was produced on every slope of the pipe is a bubble, elongated bubble, plug, plug-slug transition, plug bubble, bubble slug, slug, stratified wavy and stratified with mixture interfaces. On the upward slope of the bubble flow patterns likely to appear more and result the highest pressure of $1690 \mathrm{~N} / \mathrm{m} 2$ on Jmix $=9.3 \mathrm{~m} / \mathrm{s}$, on the horizontal position bubble slug flow pattern that often appears with the highest pressure drop of $593 \mathrm{~N} / \mathrm{m}^{2}$ on Jmix $=8.23 \mathrm{~m} / \mathrm{s}$, while the downward slope of the wavy stratified flow pattern likely to appear more with the highest pressure drop of $685 \mathrm{~N} / \mathrm{m}^{2}$ on Jmix $=5.88 \mathrm{~m} / \mathrm{s}$.
\end{abstract}

\section{Introduction}

On the industry often encountered two-phase flow, which is part of the multiphase flow. A form or phase of a substance in the two-phase flow can be divided into three: liquid, solid, and gas. Two-phase flow more encountered both in everyday life and in industrial processes, such as boilers, condensers, heat exchangers, nuclear reactors, natural gas liquefaction, and flows in the petroleum industry.

Multiphase flow is divided into several phases' combinations among others the solid-liquid, liquid-gas and solid-gas. It is very important to study the flow pattern from the two-phase flow. The Flow that is changing the flow pattern can cause pressure drop fluctuating. Therefore it is necessary for us to know and identify the flow patterns that occur to predict the pressure drop relationships with the two-phase flow, on a variety of pipe slope orientation.

The result [8] showed that the fluctuation pressure differential of slug flow is very influenced by the superficial velocity of the fluid. [5] describes the visualisation of the air-water mixture flow in a vertical pipe that is heated. The result showed that the heat transfer coefficient of air-water flow increase with increasing air flow and water flow was represented by the superficial velocity of water.

A multiphase flow related to solid, liquid or gas. Multiphase flow is the mixture flow of phases such as bubble flow which shows gas (bubble) in liquid or liquid in gas or a combination of solid, liquid and gas simultaneously in the same pipe. Many engineering and scientific applications of the multiphase, such as gas-liquid flow, solid-liquid (slurry), gas-oilwater (petroleum Industry) and many others applications of the multiphase.

The research about flow regime in horizontal and vertical pipe has been studied by [1] which can be seen in figure 1 and 2 .

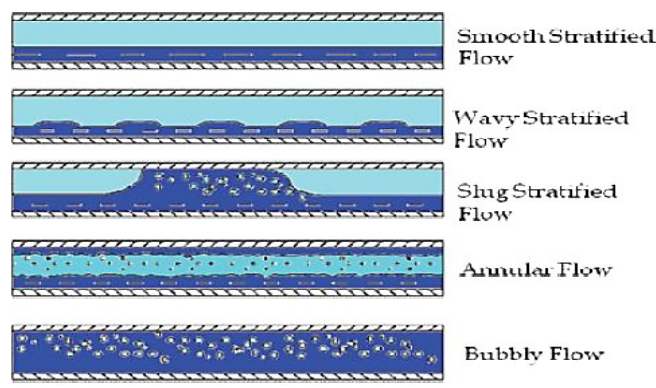

Fig.1. Flow regime in the horizontal pipe [1]

The flow pattern consists of:

a. Bubbles flow (bubble), where the gas bubbles tend to flow at the top of the tube.

b. The flow of gas bag (plug), in which small gas bubbles combine to form gas pockets.

c. Smooth stratified flow, where the interface of the liquid-gas is very smooth, but the flow pattern like this usually does not happen. The interface is almost always wavy (stratified wavy).

d. Stratified wavy occurred when gas velocity increases.

\footnotetext{
* Corresponding author: dewipuspitasari@unsri.ac.id
} 
e. Liquid plug flow (slug), which are typical large amplitude waves to reach the top of the tube.

f. Flow ring (annular), is same with the vertical tube flow, but film liquid in the bottom is thicker from the top.

The flow patterns in the vertical pipe can be seen in the figure 2 .
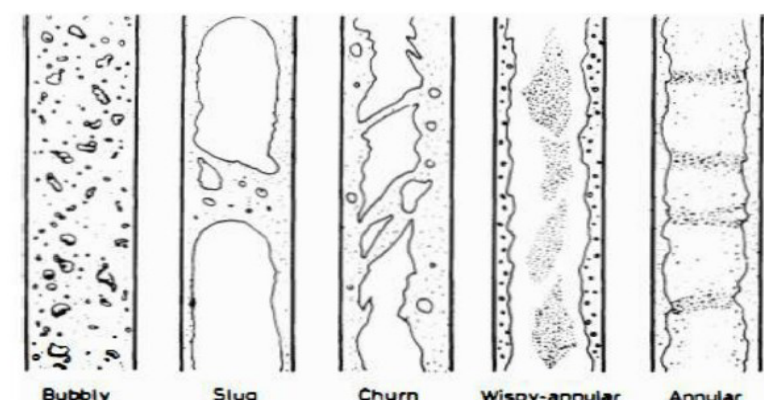

Fig.2. Flow regime in a vertical pipe [1]

The flow pattern consists of:

a. Bubble Flow, where the vapor bubbles are estimated to have the uniform size.

b. Slug Flow, gas flowing to form large bubbles (sometimes distributed small gas bubbles in the liquid)

c. Churn Flow, the oscillating movement occurs so that the liquid becomes unstable.

d. Wispy-Annular Flow, the concentration of droplets in the gas increases and merge to form wisp.

e. Annular Flow, a part of liquid phase as a film in the tube wall, and the other part in the form of droplets distributed in the gas flowing in the middle of the tube.

Hold-up of liquid $\left(\alpha_{\mathrm{L}}\right)$ is defined as the ratio between the volume occupied by the liquid phase with overall mixture volume, whereas Hold-up for gas $\left(\alpha_{g}\right)$ is the ratio between the volume occupied by the gas phase with the overall mixture volume.

$$
\begin{aligned}
& \alpha_{\mathrm{L}}=\frac{\mathrm{v}_{\mathrm{L}}}{\mathrm{v}_{\mathrm{p}}} \\
& \alpha_{\mathrm{g}}=\frac{\mathrm{v}_{\mathrm{g}}}{\mathrm{v}_{\mathrm{p}}}=1-\alpha_{\mathrm{L}}
\end{aligned}
$$

where :

$\alpha_{\mathrm{L}}=$ Hold up for liquid

$\alpha_{\mathrm{g}}=$ Hold up for gas

$\mathrm{V}_{\mathrm{L}}=$ Volume of liquid filled in pipe $\left(\mathrm{m}^{3}\right)$

$\mathrm{V}_{\mathrm{g}}=$ volume of gas filled in pipe $\left(\mathrm{m}^{3}\right)$

$V_{P}=$ Volume of mixture filled in pipe $\left(\mathrm{m}^{3}\right)$

Parameter flow used in the calculation of multiphase flow is the superficial velocity which is defined as follows:

$$
\mathrm{J}=\mathrm{Q}_{\mathrm{tot}} / \mathrm{A} \cdot \alpha
$$

where :

$\mathrm{J}=$ superficial velocity of the phase, $\mathrm{m} / \mathrm{s}$

Qtot $=$ total flow rate, $\mathrm{m}^{3} / \mathrm{s}$
$\mathrm{A}=$ pipe cross-sectional area, $\mathrm{m}^{2}$

$\alpha=$ Phase hold up

The superficial velocity of mixture is determined by the equation :

$$
\mathrm{J}_{\mathrm{m}}=\mathrm{J}_{\mathrm{L}}+\mathrm{J}_{\mathrm{g}}
$$

The pressure distribution in multiphase flow is determined from the measured from the column manometer.

\section{Methodology}

The study was conducted by using the experimental set up as shown in figure 3 .

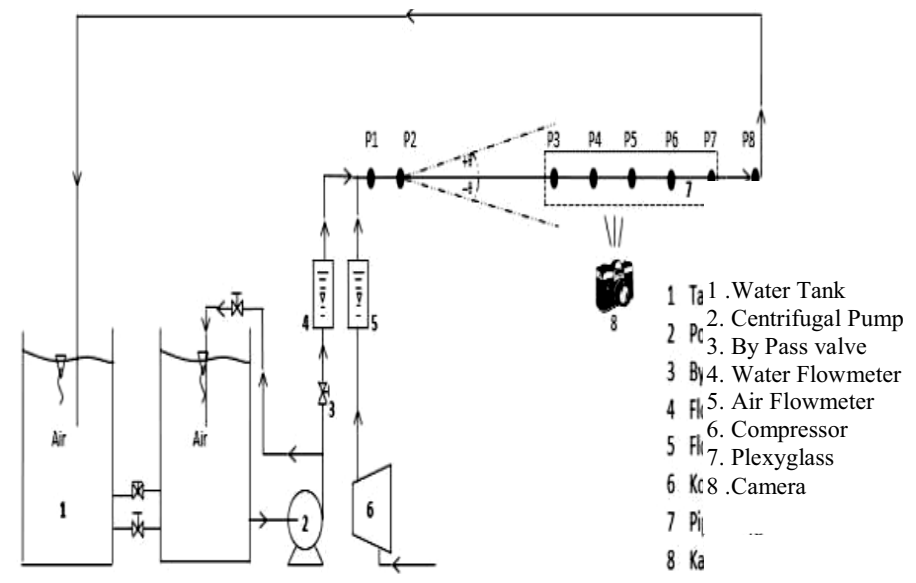

Fig.3. Schematic diagram of experimental set up

Table.1. Properties of work fluid

\begin{tabular}{ccc}
\hline Work fluid & Density $\left(\mathbf{k g} / \mathbf{m}^{\mathbf{3}}\right)$ & Viscosity $\mathbf{( k g / m . s )}$ \\
\hline Water & 998 & 0.001002 \\
Air & 1.29 & 0.000019 \\
\hline
\end{tabular}

\section{Results and discussion}

From the research results the flow pattern visualisation and pressure distribution according to variation superficial velocity and orientation of pipe slope. There were nine flow pattern results as shown in figure 4 to figure 12 .
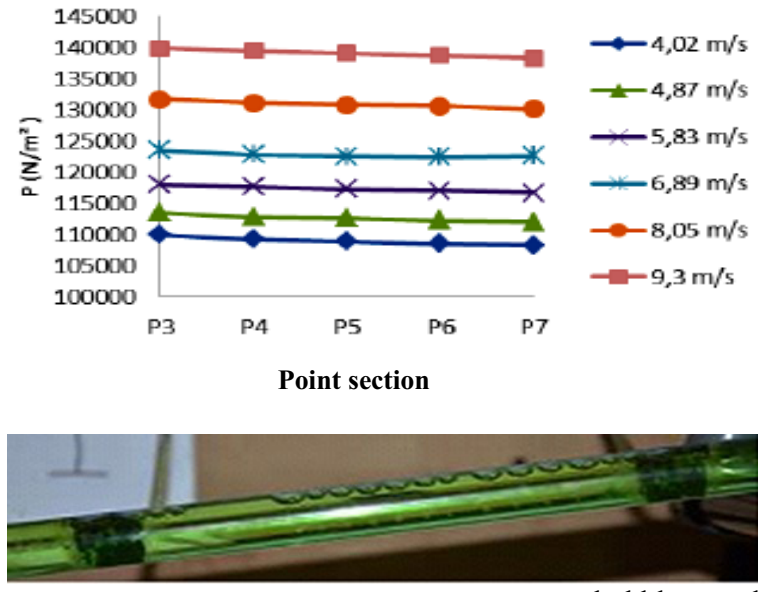

Fig.4. The pressure distribution and flow pattern bubble on the uppward $10^{\circ}$ 

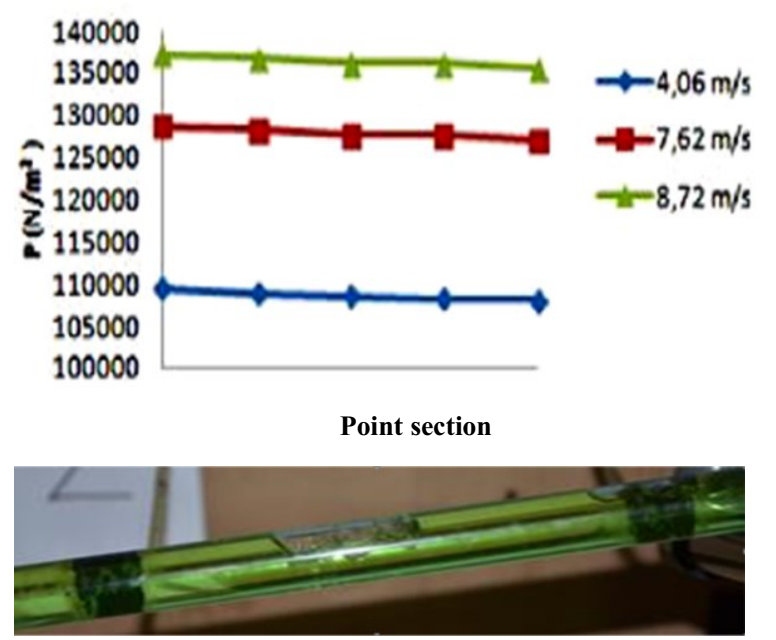

Fig.5. The pressure distribution and flow pattern elongated bubble on the upward $10^{\circ}$
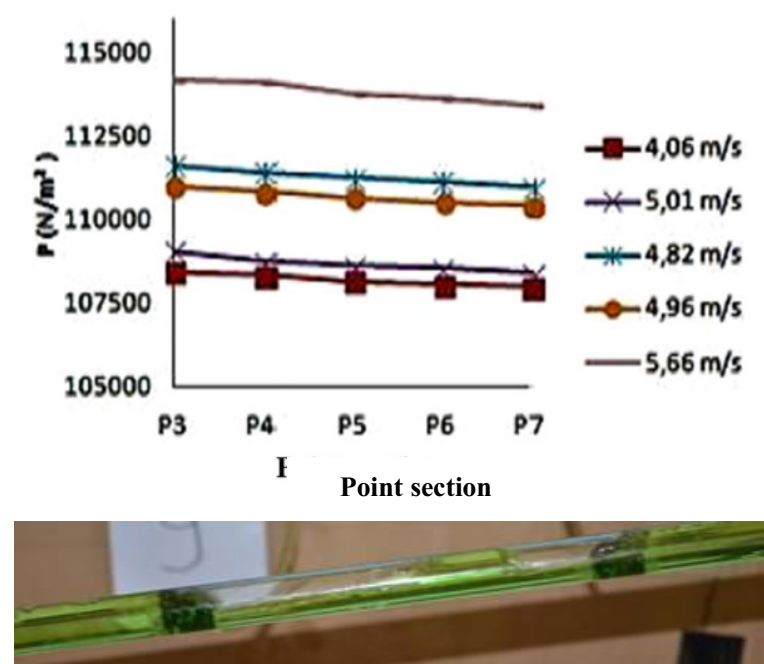

Fig.6. The pressure distribution and flow pattern plug on the upward $5^{\circ}$

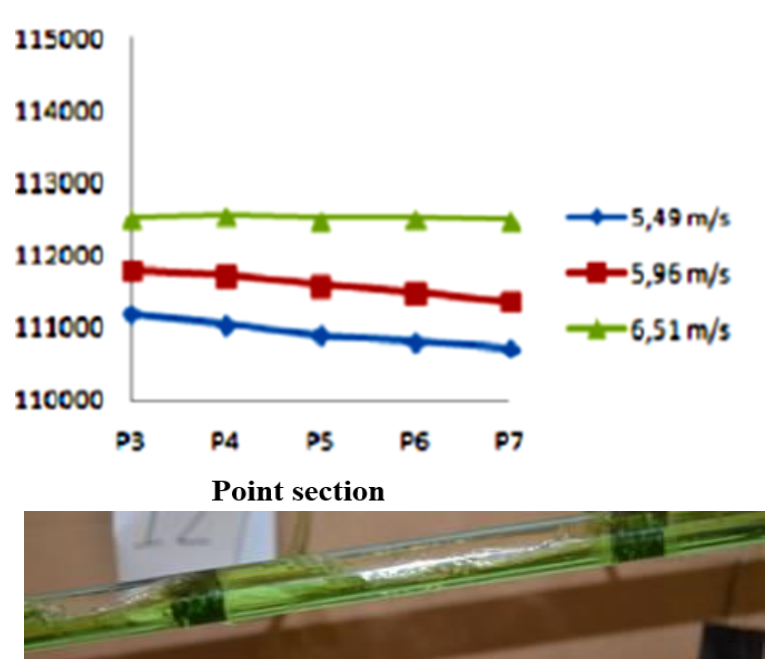

Fig.7. The pressure distribution and flow pattern plug slug on the upward $5^{\circ}$

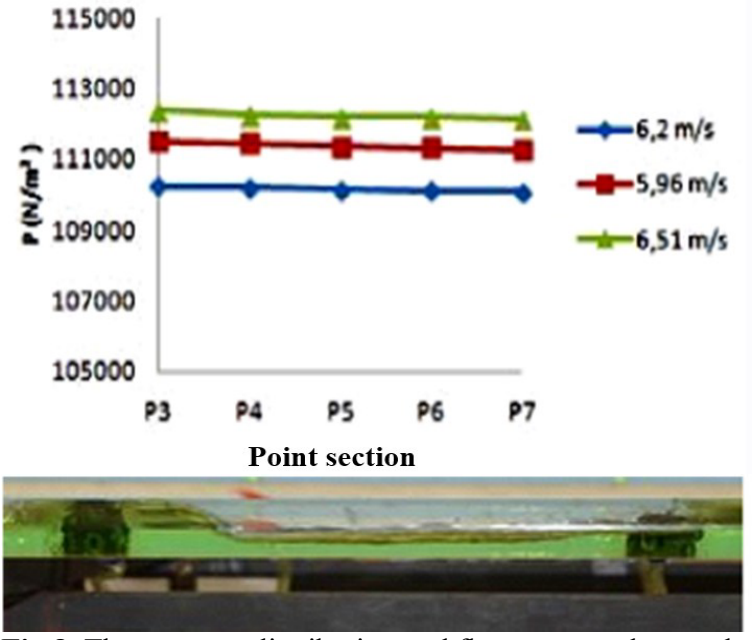

Fig.8. The pressure distribution and flow pattern slug on the horizontal $0^{\circ}$
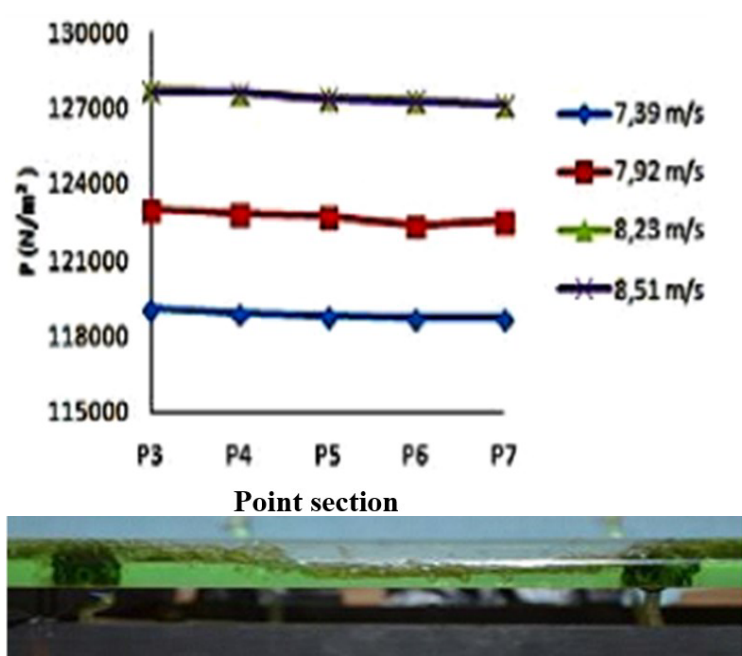

Fig.9. The pressure distribution and flow pattern slug bubble on the horizontal $0^{\circ}$
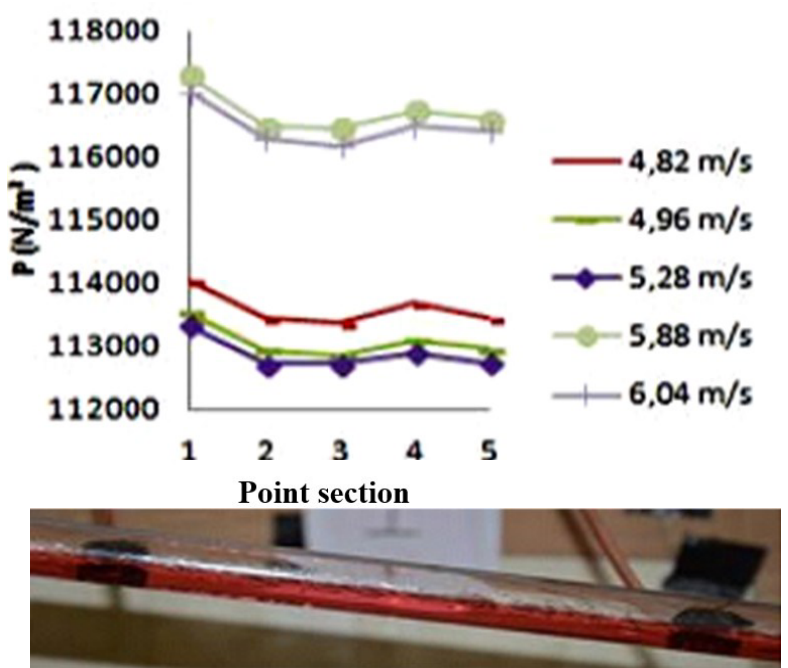

Fig.10. The pressure distribution and flow pattern stratified wavy on the downward $-5^{\circ}$ 


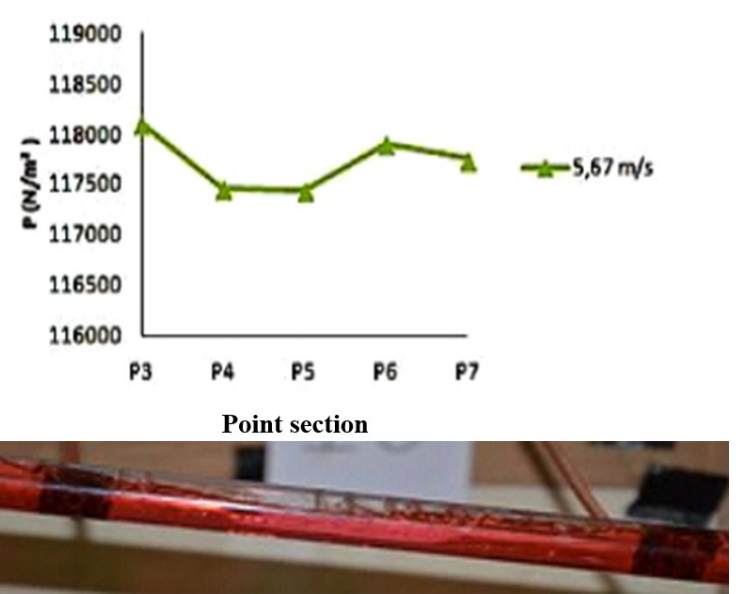

Fig.11. The pressure distribution and flow pattern plug bubble on the downward slope $-5^{\circ}$
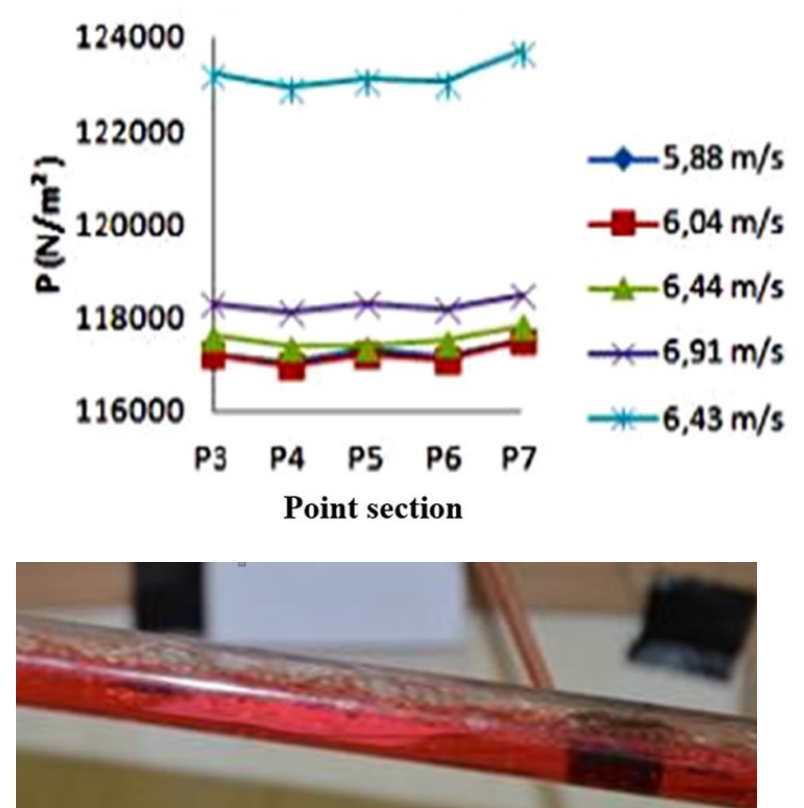

Fig.12. The pressure distribution and flow pattern stratifiedmixture interface on the downward $-10^{\circ}$

The discussion of the research just focused on the flow patterns that often appear and highly fluctuating pressure distribution.

On the upward slope $10^{\circ}$ flow patern form are : bubble, elongated bubble, plug, transition slug-plug, slug, and plug bubble. The lowest pressure drop for bubble flow is $887 \mathrm{~N} / \mathrm{m}^{2}$ on $\mathrm{J}_{\text {mix }}=6.89 \mathrm{~m} / \mathrm{s}$ and the highest is $1690 \mathrm{~N} / \mathrm{m}^{2}$ on $\mathrm{J}_{\text {mix }}=4.02 \mathrm{~m} / \mathrm{s}$. For elongated bubble flow the lowest is $1462 \mathrm{~N} / \mathrm{m}^{2}$ on $\mathrm{J}_{\text {mix }}=4.06 \mathrm{~m} / \mathrm{s}$ and the highest is $1648 \mathrm{~N} / \mathrm{m}^{2}$ on $\mathrm{J}_{\text {mix }}=8.72 \mathrm{~m} / \mathrm{s}$. This phenomenin shows that small gas bubble can combine to elongated bubble when gas flow increase. The formation of flow pattern held by the gravity in this slope, that why the pressure drop is high enought.

On the upward slope $5^{\circ}$ flow pattern form are : bubble, plug, slug, transition slug-plug, plug bubble, and the slug bubble. The lowest pressure drop for plug flow is $452 \mathrm{~N} / \mathrm{m}^{2}$ on $\mathrm{J}_{\text {mix }}=4.06 \mathrm{~m} / \mathrm{s}$ and the highest is 741 $\mathrm{N} / \mathrm{m}^{2}$ on $J_{\text {mix }}=5.66 \mathrm{~m} / \mathrm{s}$. For slug flow the lowest is 39 $\mathrm{N} / \mathrm{m}^{2}$ on $J_{\text {mix }}=6.51 \mathrm{~m} / \mathrm{s}$ and the highest is $454 \mathrm{~N} / \mathrm{m}^{2}$ on $\mathrm{J}_{\text {mix }}=5.49 \mathrm{~m} / \mathrm{s}$. If gas flow increases the flow pattern can be form to plug, for this condition the amplitude the gas reach the upper pipe and press the water in the bottom with the thin layer, if gas flow is more the flow pattern become plug slug whereas slug in the front section and slug in the rear section, some times was form to combination slug plug. Pressure drop in upward $5^{\circ}$ was lower than upward $10^{\circ}$, because an effect of gravity was decreased.

On the horizontal slope, $0^{\circ}$ flow pattern form are : elongated bubble, plug, slug, transition slug-plug, plug bubble and slug bubble. The lowest pressure drop for slug flow is $156 \mathrm{~N} / \mathrm{m}^{2}$ on $\mathrm{J}_{\text {mix }}=6.2 \mathrm{~m} / \mathrm{s}$ and the highest is $235 \mathrm{~N} / \mathrm{m}^{2}$ on $J_{\text {mix }}=5.96 \mathrm{~m} / \mathrm{s}$. For slug bubble flow the lowest is $353 \mathrm{~N} / \mathrm{m}^{2}$ on $J_{\text {mix }}=7.39 \mathrm{~m} / \mathrm{s}$ and the highest is $593 \mathrm{~N} / \mathrm{m}^{2}$ on $J_{\text {mix }}=8.23 \mathrm{~m} / \mathrm{s}$. In this slope the gravity effect was neutral, therefore slug flow becomes slug bubbles with the small area than slug when gas flow increase, but the distribution of pressure become increase very high suddenly, this cause by the existence bubble in the upper of slug layer.

On downward slope $-5^{\circ}$ flow pattern form are : stratified wavy, plug, bubble, elongated bubble, plug bubble and stratified with mixture interface. The lowest pressure drop for stratified wavy flow is $587 \mathrm{~N} / \mathrm{m}^{2}$ on $\mathrm{J}_{\text {mix }}=4.82 \mathrm{~m} / \mathrm{s}$ and the highest is $685 \mathrm{~N} / \mathrm{m}^{2}$ on $\mathrm{J}_{\text {mix }}=5.88$ $\mathrm{m} / \mathrm{s}$. For plug bubble flow there is only one flow pattern was found then the pressure distribution is $342 \mathrm{~N} / \mathrm{m}^{2}$ on $\mathrm{J}_{\text {mix }}=5.67 \mathrm{~m} / \mathrm{s}$. Flow pattern stratified wavy become to form plug bubble when gas flow increase, but the pressure drop is lower because gas layer become small and water is dominant in this section. for this slope, effect the gravity play a role again but not significant.

On the downward slope $-10^{\circ}$ flow pattern stratified wavy, plug, bubble, elongated bubble, plug, transition slug-plug, slug, atnd stratified with mixture interface. The lowest pressure drop for stratified with mixture interface flow is $184 \mathrm{~N} / \mathrm{m}^{2}$ on $J_{\text {mix }}=6.91 \mathrm{~m} / \mathrm{s}$ and the highest is $1690 \mathrm{~N} / \mathrm{m}^{2}$ on $\mathrm{J}_{\text {mix }}=4.02 \mathrm{~m} / \mathrm{s}$. For elongated bubble flow the lowest is $450 \mathrm{~N} / \mathrm{m}^{2}$ on $\mathrm{J}_{\text {mix }}=6.43 \mathrm{~m} / \mathrm{s}$. For this slope, the effect of gravity was significant, that why flow pattern become stratified wavy with mixture interface and pressure drop higher same with upward $10^{\circ}$.

\section{Conclusion}

1. The flow patterns were found throughout the study for each slope are : bubble, elongated bubble, transition plug-slug, plug-slug, plug bubble, slug bubble, stratified wavy, and stratified with mixture interface.

2. The pressure drop for each flow patterns in the variation of the slope is different. For upward slope $10^{\circ}$ highest pressure drop is achieved under conditions bubble flow with a drop of pressure of $1690 \mathrm{~N} / \mathrm{m}^{2}$ and $\mathrm{J}_{\text {mix }}=4.02 \mathrm{~m} / \mathrm{s}$. The lower of $\mathrm{J}_{\text {mix }}$ the higher of pressure drop.

3. On the upward slope of $5^{\circ}$ highest pressure drop occurs in the Plug flow of $741 \mathrm{~N} / \mathrm{m}^{2}$ with $J_{\text {mix }}=5.66$ $\mathrm{m} / \mathrm{s}$. In the horizontal position $\left(0^{\circ}\right)$ highest pressure 
drop occurs in slug bubble flow of $593 \mathrm{~N} / \mathrm{m}^{2}$ on $J_{\text {mix }}$ $=8.23 \mathrm{~m} / \mathrm{s}$.

4. On the downward slope of the highest pressure drop occurs in conditions the Stratified wavy flow of 685 $\mathrm{N} / \mathrm{m}^{2}$ with $\mathrm{J}_{\text {mix }}=5.88 \mathrm{~m} / \mathrm{s}$.

We acknowledge for the University of Sriwijaya as my institution, that has provided research grants PNBP 2016. My beloved family who always supports me to write the scientific paper more and more.

\section{References}

1. Boyun, Guo. Offshore Pipelines (University of Louisiana at Lafayette, 2005)

2. I Kadek EHW, J. mechanical engineering Bali State Polytechnic, Bali (2015)
3. Korawan, A.D., Yuwono, T. J. Mechanical Engineering Institute of Technology (2015)

4. Livia A et al, The 13th Brazilian Congress of Thermal Science and Engineering (2010)

5. Kunarto, J. Mechanical Engineering University of Bandar Lampung (2011)

6. Munson, B. R., Young, D. F., and Okiishi, T. H., Fluid Mechanics (Translation by Dr. Ir. Harinaldi and Ir. Budiarso, M.Eng), Volume 1, Edition 4. Jakarta, Erland, 2003)

7. Priyo H A, J. Mechanical Engineering, State University of Surabaya (2010)

8. Santoso, Budi., et all., J. Mechanical and Industrial Engineering University of Gadjah Mada (2012) 